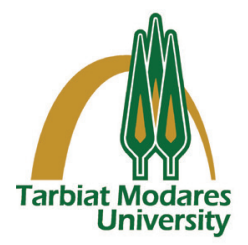

\title{
Evaluation of Fecal Colonization with Extended-Spectrum Beta-Lactamase-Producing Enterobacteriaceae and Risk Factors among Cancer Patients in Eastern Iran
}

\section{A R T I C L E I N F O}

Article Type

Original Research

Authors

Parvin Askari, $P h D^{1}$

Farzane Hakimi, $M D^{2}$

Marzieh Moghanni, $M S c^{3}$

Ahmad Reza Sebzari, $M D^{4}$

Mohammad Hasan Namaei, $P h D^{5 *}$

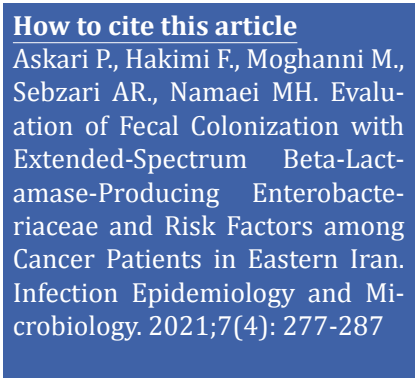

${ }^{1}$ Department of Microbiology, School of Medicine, Birjand University of Medical Sciences, Birjand, Iran. ${ }^{2}$ Faculty of Medicine, Birjand University of Medical Sciences, Birjand, Iran.

${ }^{3}$ Faculty of Health, Birjand University of Medical Sciences, Birjand, Iran.

${ }^{4}$ Radiation Oncology, Clinical

Research Development Unit (CRDU), ValiAsr Hospital, Birjand University of Medical Sciences, Birjand, Iran ${ }^{5}$ Infectious Diseases Research Center, Birjand University of Medical Sciences(BUMS), Birjand, Iran.

\section{* Correspondence}

Address: Infectious Diseases Research Center, Birjand University of Medical Sciences (BUMS), Birjand, South Khorasan Province, Iran. mhnamaei@hotmail.com

\section{A B S T R A C T}

Background: This research aimed to estimate the prevalence of extended-spectrum b-lactamase-producing Enterobacteriaceae (ESBL-PE) in stool samples of patients with different types of cancer.

Materials and Methods: Stool samples or deep rectal swabs were collected from cancer cases from January 2017 to December 2018. After species identification, in order to detect ESBLPE, double-disk synergy test (DD test) was used. Disk diffusion procedure was conducted to determine the susceptibility of bacteria to antimicrobials. Lastly, antibiotic resistance genes including bla genes were characterized via polymerase chain reaction (PCR).

Findings: Among 100 patients enrolled in this study, 50 (50\%) were ESBL carriers. Escherichia coli was the most prevalent bacterium isolated (85\%). Genotyping of EBSL-PE encoding genes using PCR showed that the prevalence rates of $b l a_{\text {CTX-M }}$ and $b l a_{\text {CTX-M-15 }}$ genes were 94 ( 47 of 50) and 90\% (45 of 50), respectively, which were higher than those of $b^{2} a_{\text {тЕм }}$ $(80 \%, 40$ of 50$)$ and $b l a_{\text {SHV }}$ genes $(34 \%, 17$ of 50$)$. There was no significant association between ESBL-PE fecal carriage and age $(p=.68)$, sex $(p=.49)$, time of diagnosis $(p=.21)$, antibiotic therapy for the past three months $(p=.77)$, and history of chemotherapy $(p=.49)$. Finally, it was determined that cancer type was an associated risk factor for ESBL-PE fecal carriage in cancer patients.

Conclusion: This research emphasizes regular bacterial monitoring, and that antibiotic stewardship plans ought to be performed among cancer patients to prohibit further spread of ESBL-PE with confined therapeutic options.

Keywords: Enterobacteriaceae extended-spectrum beta-lactamase, Fecal carriage, Cancer patients, Iran.

\section{CITATION LINKS}

[1] Lin L, Jia L, Fu Y, Zhao R, Huang Y, Tang C, et al. A comparative analysis ... [2] Jiang A-M, Shi X, Liu N, Gao H, Ren M-D, Zheng X-Q, et al. Nosocomial... [3] Mahamat OO, Lounnas M, Hide M, Dumont Y, Tidjani A, Kamougam K, et al. High prevalence and characterization of... [4] Ali T, Ali I, Khan NA... [5] ElMahallawy HA, Zafer MM, Amin MA, Ragab MM, Al-Agamy MH. Spread of carbapenem... [6] Medboua-Benbalagh C, Touati A, Kermas R, Gharout-Sait A, Brasme L, Mezhoud H, et al. Fecal carriage of extended-spectrum $\beta$-lactamase-producing Enterobacteriaceae strains is associated with worse outcome in patients hospitalized in... [7] Montassier E, Batard E, Gastinne T, Potel G, de La Cochetière M. Recent changes in bacteremia in patients with cancer: a systematic review of... [8] Arnan M, Gudiol C, Calatayud L, Liñares J, Dominguez M, Batlle M, et al. Risk... [9] Gudiol C, Calatayud L, Garcia-Vidal C, LoraTamayo J, Cisnal M, Duarte R, et al. Bacteraemia due to... [10] Kim Y-J, Jung SM, Kang J, Ryoo SM, Sohn CH, Seo D-W, et al. Risk factors for extended-spectrum beta-lactamase-producing Enterobacteriaceae infection causing septic shock in cancer patients with... [11] Marin M, Gudiol C, Ardanuy C, Garcia-Vidal C, Calvo M, ... [12] SG S, Nath DR. Prevalence of ESBL and Amp C producing Enterobacteriaceae in a tertiary care cancer hospital in South India with special reference to E. coli and Klebsiellapneumoniae... [13] Clinical, Institute LS. ... [14] Joo E-J, Kim SJ, Baek M, Choi Y, Seo J, Yeom J-S, et al. Fecal carriage of antimicrobial-resistant Enterobacteriaceae in healthy Korean... [15] Sheikh AF, Moosavian M, Abdi M, Heidary M, Shahi F, Jomehzadeh N, et al. Prevalence... [16] Montazeri EA, Khosravi AD, Saki M, Sirous M, Keikhaei B, Seyed-Mohammadi S. Prevalence of Extended-Spectrum... [17] Calatayud L, Arnan M, Liñares J, Dominguez M, Gudiol C, Carratalà J, et al. Prospective... [18] Golzarri MF, Cornejo-Juárez P, Chora-Hernández LD, Vilar-Compte D. Colonization by fecal extendedspectrum... [19] Christophy R, Osman M, Mallat H, Achkar M, Ziedeh A, Moukaddem W, et al. Prevalence, antibiotic... [20] Cornejo-Juárez P, Suárez-Cuenca JA, Volkow-Fernández P, SilvaSánchez... [21] Knudsen PK, Brandtzaeg P, Høiby EA... [22] Melzer M, Petersen I. Mortality... [23] Moghanni M, Ghazvini K, Farsiani H, Namaei MH, Derakhshan M, Yousefi M, et al... [24] Bourouis A... [25] Namaei MH, Yousefi M, Ziaee M, Salehabadi A, Ghannadkafi M, Amini E, et al. First... [26] Hassuna NA, Khairalla AS, Farahat EM, Hammad AM, Abdel-Fattah M. Molecular...
Received: July 052021

Accepted: September 25,2021

Published: November 25,2021

Copyright(C) 2021, TMU Press. This open-access article is published under the terms of the Creative Commons Attribution-NonCommercial 4.0 International License which permits Share (copy and redistribute the material in any medium or format) and Adapt (remix, transform, and build upon the material) under the Attribution-NonCommercial terms. 


\section{Introduction}

Many studies have revealed that there is a strong relationship between malignancy and microbial infections ${ }^{[1]}$. Studies have shown that bacterial infections are the most current problems in cancer cases because they are likely to get immunodeficiency disorders owing to undernutrition, surgical or invasive procedures, chemotherapy, radiation therapy, and treatment interference [2]. Infectious diseases are one of the salient non-cancerous causes of death in cancer cases. In developing countries, infections cause the death of one in five cancer patients ${ }^{[1]}$.

Infections caused by resistant Gramnegative bacteria are a major universal health challenge because of their difficult treatment and high mortality. The extendedspectrum beta-lactamase producing Enterobacteriaceae bacteria (ESBL-PE) have become a rather outstanding problem [1]. ESBLs display resistance to many antibiotics, such as cephalosporins, penicillins, and aztreonam ${ }^{[3]}$. Drug resistance in ESBL-PE isolates is related to the manufacture of resistance enzymes like beta-lactamases and extended-spectrum beta-lactamases, of which the CTX-M, TEM, and SHV betalactamases are the typical forms ${ }^{[4]}$.

In cancer cases, the gastrointestinal tract is a main endogenous source of infectious organisms, and intestinal colonization is a prelude to intestinal transposition and systemic dispensation of bacteria ${ }^{[5]}$. In a study, $54 \%$ of children with various types of cancer in the oncology ward were carriers of ESBL, of which CTX-M of ESBLtype was the most common ${ }^{[6]}$. In a study in Spain, ESBL-producing Escherichia coli (ESBL-EC) fecal carriage was found in $29 \%$ of neutropenic patients with hematological malignancies, and previous antibiotic therapy in neutropenic cancer patients was determined to be effective in EC fecal colonization. Analysis of ESBL-
EC strains isolated from fecal samples indicated a polyclonal distribution with CTX-M superiority (CTX-M 82\%, SHV 15\%, TEM 3\%) [7, 8]. In another study in Spain, ESBL-EC bacteremia was common among cancer patients, particularly those under antibiotic pressure, and most ESBL-EC strains contained the CTX-M group enzymes [9]. In a study conducted during 2012-2018 in Korea, ESBL-PE accounted for $12.8 \%$ of sepsis cases among patients suffering from chemotherapy-induced neutropenia ${ }^{[10]}$. A study in western China showed that ESBLPE members were mostly (72.8\%) MDR strains isolated from cancer patients with nosocomial infections ${ }^{[2]}$. In 2014, ESBL-PE isolates were shown in a study to be the most prevalent bacteria causing bloodstream infections in hematological cancer cases [11]. In another study conducted in Spain, ESBL-EC fecal carriage was regarded as a risk factor for bloodstream infections (BSI) in immunosuppressed patients with higher mortality compared with non-ESBL-EC ${ }^{[6]}$. ESBL-PE fecal carriage is an important risk factor for subsequent infections by these microorganisms [6]. Infections caused by these resistant organisms have limited treatment options, have a poorer prognosis, and are less cost-effective. Hence, inability to detect these resistant enzymes contributes to their uncontrolled dispersion, outbreaks, and sometimes avoidable remedial failures [12]. As far as we know, no research has been conducted in Iran to assess the prevalence of ESBL-PE fecal carriage and its relationship with infections in cancer patients.

Objectives: theobjective of thisresearchwas to study the prevalence of gastrointestinal colonization with ESBL-PE in patients suffering from various types of cancer and to ascertain its relationship with age, sex, type of malignancy, duration of cancer, and history of antibiotic consumption in these patients. 


\section{Materials and Methods}

Sampling: In this cross-sectional study, fecal samples were collected from 100 cancer patients (breast, gastrointestinal, genitourinary, skin, and lung cancers) who referred to the oncology units of two educational hospitals (Imam Reza and Vali-e-Asr). The average age of cancer cases was $57.11 \pm 16.14$ (SD) years, of whom $64 \%$ were female, and the rest were male. One hundred stool samples or deeprectal swabs (disable patients) were collected from January 2017 to December 2018 and promptly transported to the laboratory in a thermostatic container. All samples were stored at $4{ }^{\circ} \mathrm{C}$. Statistical information was collected from all patients, including age, sex, and history of antibiotic use within the past three months, time of diagnosis, history of anticancer chemotherapy, and cancer type.

The inclusion criteria were as follows: a) patients who accepted to take part in this study, and b) all patients who had pathologyconfirmed cancer.

Exclusion criteria were also as follows: a) fecal samples of patients who died before the end of the study, b) patient dissatisfaction to complete the study, and c) intake of probiotics within four weeks prior to the study, which might have influenced the gut milieu.

Microbial Identification: Stool samples were vortexed in $1 \mathrm{~mL}$ of sterile phosphatebuffered saline (PBS). Then the samples were cultured on two plates, containing MacConkey agar supplemented with cefotaxime $(4 \mu \mathrm{g} / \mathrm{mL})$ and ceftazidime (4 $\mu \mathrm{g} / \mathrm{mL}$ ), and incubated at $37^{\circ} \mathrm{C}$ for 24 hours [6]. Bacterial colonies were identified based on standard biochemical tests, including oxidase, triple sugar iron agar (TSI), Simmon citrate, indole production, urease, and methyl red/Voges-Proskauer (MR-VP). All media were provided from Merck Co., Darmstadt, Germany. Then colonies with morphologies similar to Enterobacteriaceae were isolated and stored in tryptic soy broth
(TSB) with $15 \%$ glycerol at $-25^{\circ} \mathrm{C}$.

Antimicrobial Sensitivity Testing: Antimicrobial sensitivity testing was conducted for Enterobacteriaceae isolates by applying the disc diffusion method under the guidelines of the Clinical and Laboratory Standards Institute (CLSI, 2017) using commercially accessible discs (Mast, UK), including cefotaxime $(30 \mu \mathrm{g})$, ceftazidime (30 $\mu \mathrm{g})$, ciprofloxacin $(5 \mu \mathrm{g})$, gentamicin $(10 \mu \mathrm{g})$, imipenem (10 $\mu \mathrm{g})$, amikacin (30 mg), and levofloxacin (5 $\mu \mathrm{g})$. E. coli ATCC 25922 was used as a quality control strain ${ }^{[13] .}$

Phenotypic Detection of ESBLs: A doubledisk synergy test (DD test) was applied to screen for ESBL-producing isolates., such as ceftazidime and cefotaxime alone, ceftazidime + clavulanic acid, and cefotaxime + clavulanic acid (Mast group, UK) [14]. Bacterial isolates showing positive results in the DD test were further investigated using PCR to screen for ESBL determinants as described below. E. coli ATCC 25922 and Klebsiella pneumonia ATCC700603 were used as the ESBL-negative and ESBL-positive controls, respectively.

Polymerase Chain Reaction (PCR) for Detection of ESBL Genes

DNA Extraction: Total DNA was extracted from fresh colonies of Enterobacteriaceae isolates by boiling approach as described previously ${ }^{[15]}$. Briefly, 2 or 3 colonies of an overnight culture of each isolate on nutrient agar (Merck Co., Darmstadt, Germany) were suspended in $500 \mu \mathrm{L}$ of DNase- and RNasefree water. The suspension was boiled at $100{ }^{\circ} \mathrm{C}$ for $10 \mathrm{~min}$ in a dry block incubator and then centrifuged at $14,000 \mathrm{~g}$ for $10 \mathrm{~min}$. Subsequently, $0.5 \mathrm{~mL}$ of the supernatant was used as a DNA template for PCR. The extracted DNA was stored at $20-{ }^{\circ} \mathrm{C}$ until used for analysis [16].

PCR Protocol: The existence of $b l a_{\text {Стх-м' }}$ $b l a_{\mathrm{TEM}}, b l a_{\mathrm{SHV}}$, and $b l a_{\text {СТX-M-15 }}$ in phenotypic ESBL-positive isolates in DDT was examined 
by PCR using specific primers delineated in Table 1. The PCR amplification was carried out within a PeqSTAR 2X thermal cycler (PEQLAB, Germany) in a final volume of $20 \mu \mathrm{L}$ containing $10 \mu \mathrm{L}$ of Taq $2 \mathrm{X}$ Master Mix, $1 \mu \mathrm{L}$ of every primer (10 pmol), $2 \mu \mathrm{L}$ of sample DNA, and $6 \mu \mathrm{L}$ of nuclease-free water. The PCR thermal cycling conditions were as follows: an initial denaturation step at $94{ }^{\circ} \mathrm{C}$ for $5 \mathrm{~min}$, followed by 35 cycles of denaturation at $95{ }^{\circ} \mathrm{C}$ for $35 \mathrm{~s}$, annealing at different temperatures (Table 1) for $35 \mathrm{~s}$, extension at $72{ }^{\circ} \mathrm{C}$ for $30 \mathrm{~s}$, and a terminal extension step at $72{ }^{\circ} \mathrm{C}$ for 5 min. The amplicons were analyzed using agarose gel electrophoresis, stained with green viewer stain (parstous Co., Tehran, Iran), and visualized using an ultraviolet gel documentation device (Herolab, Germany). A positive control factor was provided from Pasteur Institute of Iran.

Statistical Analysis: SPSS software Version 22.0 was utilized for statistical analysis. The Chi-square test and Fisher's exact test, where appropriate, were conducted to compare variables. A $p$-value $<.05$ was considered statistically significant.

\section{Findings}

Characteristics of the studied population:

During this research, 100 patients with various types of cancer, who referred to the oncology units of two hospitals in Birjand city, eastern Iran, were screened for fecal ESBL-PE carriage. The female to male ratio was 1.7 (64 to 36), and the average age of patients was $57.11 \pm 16.14$ (SD) years. The most common cancers among patients were gastrointestinal, breast, genitourinary, skin, and lung cancers with prevalence rates of 40 (\%40), 35 (\%35), 15 (\%15), \%3)3), and 3 (\%3) cases, respectively. Only \%35 of patients had received antibiotics in the past three months prior to sampling. Most subjects (\%80) had a history of cancer chemotherapy. In $\% 51$ of patients, the time of cancer diagnosis was related to the past two to five years. The clinical and demographic profiles of the subjects are exhibited in Table 2 .

Species Identification: During the study period, in culture medium containing cefotaxime and ceftazidime, bacterial growth was observed in 54 (54\%) out of 100 samples tested, and a total of seven different colonies were isolated. Based on colony morphology and conventional biochemical tests, E. coli $(46,85 \%)$ was the most prevalent bacterium isolated. The prevalence rate of other bacteria was as follows: $1(1.8 \%)$ K. oxytoca, $3(5.5 \%)$ Citrobacter freundii, 1(1.8\%) Citrobacter amaloiticous, 1(1.8\%) Morganella morganii,

Table 1) Target bla genes and used primers in this research

\begin{tabular}{|c|c|c|c|c|}
\hline Primer & Sequence $\left(5^{\prime}-3^{\prime}\right)$ & $\begin{array}{l}\text { Products } \\
\text { Sizes (bp) }\end{array}$ & $\begin{array}{c}\text { Annealing } \\
\quad\left({ }^{\circ} \mathrm{C}\right)\end{array}$ & Reference \\
\hline$b l a_{\text {TEM }}$ & $\begin{array}{l}\text { Fw-ATGAGTATTCAACATTTCCG } \\
\text { Rv- CTGACAGTTACCAATGCT TA }\end{array}$ & 868 & 54 & (23) \\
\hline$b_{\text {SHV }}$ & $\begin{array}{l}\text { Fw- ATGCGTTATATTCGCCTGTGTAT } \\
\text { Rv- TTAGCGTTGCCAGTGCTCGATCAG }\end{array}$ & 868 & 56 & (24) \\
\hline$b l a_{\text {СТX-M }}$ & $\begin{array}{l}\text { Fw- ATGTGCAGCACCAGTAAAGT } \\
\text { Rv- ACCGCGATATCGTTGGTGG }\end{array}$ & 542 & 55 & $(25)$ \\
\hline bla $_{\text {CTX-M-15 }}$ & $\begin{array}{l}\text { Fw- ATAAAACCGGCAGCGGTG } \\
\text { Rv- GAATTTTGACGATCGGGG }\end{array}$ & 483 & 55 & (26) \\
\hline
\end{tabular}


Table 2) The baseline characteristics and clinical features of the study population

\begin{tabular}{|c|c|c|c|}
\hline Data & & Frequency (f) & Percentage (\%) \\
\hline \multirow{2}{*}{ Sex } & Male & 36 & 36 \\
\hline & Female & 64 & 64 \\
\hline \multirow{3}{*}{ Age (in years) } & $\leq 40$ & 12 & 12 \\
\hline & $41-59$ & 48 & 48 \\
\hline & $60 \leq$ & 40 & 40 \\
\hline \multirow{6}{*}{ Cancer types } & Breast & 35 & 35 \\
\hline & Gastrointestinal & 40 & 40 \\
\hline & Genitourinary & 15 & 15 \\
\hline & Skin & 3 & 3 \\
\hline & Lung & 3 & 3 \\
\hline & Others & 4 & 4 \\
\hline \multirow{4}{*}{$\begin{array}{l}\text { Time of diagnosis } \\
\text { (in years) }\end{array}$} & $<1$ & 35 & 35 \\
\hline & 1 & 7 & 7 \\
\hline & $2-5$ & 51 & 51 \\
\hline & $5<$ & 7 & 7 \\
\hline \multirow{2}{*}{$\begin{array}{l}\text { Prior antibiotic use } \\
\text { (past three months) }\end{array}$} & Positive & 38 & 38 \\
\hline & Negative & 62 & 62 \\
\hline \multirow{2}{*}{$\begin{array}{l}\text { History of cancer } \\
\text { chemotherapy }\end{array}$} & Positive & 80 & 80 \\
\hline & Negative & 20 & 20 \\
\hline
\end{tabular}

and 2(3.7\%) Pseudomonas aeruginosa. Antimicrobial susceptibility testing and Phenotypic Detection of ESBLs: Antibiotic susceptibility and DDT tests were performed on 54 Enterobacteriaceae isolates. Antimicrobial sensitivity testing showed that among the seven antimicrobial agents tested, resistance rates to $\beta$-lactam antibiotics including cefotaxime, ceftazidime, and imipenem were 51 (94.4\%), 32 (59.3\%), and 1 (1.9\%) cases, respectively. Also, levels of resistance to non$\beta$-lactam antibiotics including gentamicin, ciprofloxacin, levofloxacin, and amikacin were 8 (14.8\%), 19 (35.2\%), 19 (35.2\%), and 2 (3.7\%) cases, respectively. The highest resistance of isolates was observed against cefotaxime, and the lowest resistance was against imipenem (Figure 1).

The results of DDT showed that 50 (92.5\%) isolates were ESBL positive, whereas the remaining $4(7.4 \%)$ isolates were not ESBL producer.

In addition, there was no considerable correlation between ESBL-PE fecal carriage and age $(p$-value $=.68)$, sex ( $p$-value $=.49)$, time of diagnosis $(p$-value $=.21)$, antibiotic therapy in the past three months ( $p$-value= .77 ), and chemotherapy history ( $p$-value= .49 ) in this research (Table 3). 
Table 3) Comparative characteristics of the study population according to the extended-spectrum b-lactamase-producing Enterobacteriaceae fecal carriage

\begin{tabular}{|c|c|c|c|c|}
\hline Demographic Variable & $\begin{array}{l}\text { ESBL-Producing } \\
\text { Enterobacteriaceae } \\
\%(\mathrm{n})\end{array}$ & $\begin{array}{l}\text { Non ESBL-Producing } \\
\text { Enterobacteriaceae } \\
\%(\mathrm{n})\end{array}$ & P-value & F-Value \\
\hline $\begin{array}{l}\text { Gender } \\
\text { Male } \\
\text { Female }\end{array}$ & $\begin{array}{l}58.3(21) \\
45.3(29)\end{array}$ & $\begin{array}{l}17.58(15) \\
57.4(35)\end{array}$ & .49 & 1.58 \\
\hline $\begin{array}{l}\text { Age group (years) } \\
\leq 40 \\
41-50 \\
60 \leq\end{array}$ & $\begin{array}{l}41.7(5) \\
52.1(25) \\
50.0(20)\end{array}$ & $\begin{array}{l}58.3(7) \\
9.65(23) \\
11.12(20)\end{array}$ & .68 & 2.28 \\
\hline $\begin{array}{l}\text { Prior antibiotic use } \\
\text { (past three months) } \\
\text { Prior antibiotic use } \\
\text { No prior antibiotic use }\end{array}$ & $\begin{array}{l}47.7(18) \\
51.6(32)\end{array}$ & $\begin{array}{l}56.2(20) \\
13.83(30)\end{array}$ & .77 & 0.57 \\
\hline $\begin{array}{l}\text { Prior chemotherapy } \\
\text { No Prior chemotherapy }\end{array}$ & $\begin{array}{l}52.5(42) \\
40.0(8)\end{array}$ & $\begin{array}{l}16.73(38) \\
60.0(12)\end{array}$ & .49 & 1.33 \\
\hline $\begin{array}{l}\text { Time of diagnosis } \\
\text { (in years) } \\
<1 \\
1-5 \\
5<\end{array}$ & $\begin{array}{l}42.9(15) \\
25.14(33) \\
28.6(2)\end{array}$ & $\begin{array}{l}57.1(20) \\
35.18(25) \\
71.4(5)\end{array}$ & .21 & 7.77 \\
\hline
\end{tabular}

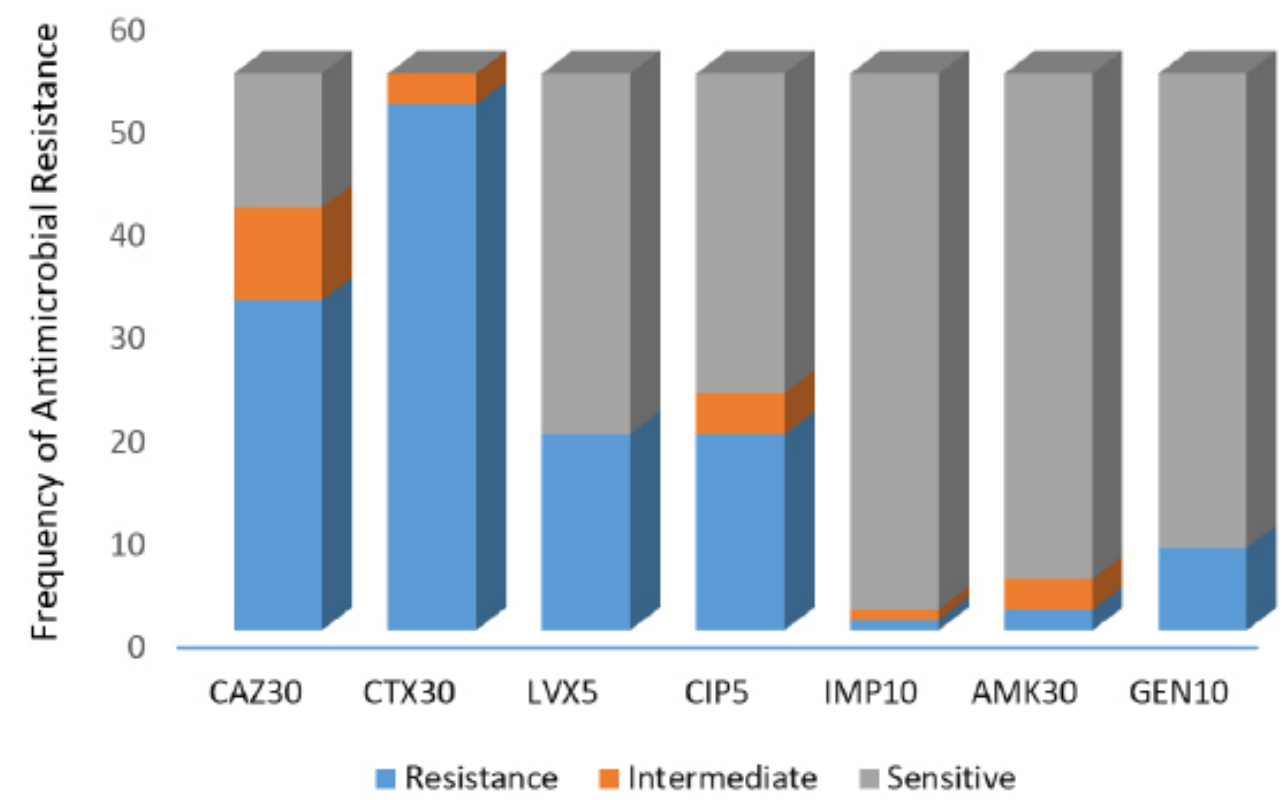

Fig. 1. Frequency of antimicrobial resistance of isolates from patients with cancer. S: susceptible, I: intermediate, R: resistant, $\mathrm{GM}_{10}$ : gentamicin, $\mathrm{AMK}_{30}$ : amikacin, $\mathrm{IPM}_{10}$ : imipenem, $\mathrm{CIP}_{5}$ : ciprofloxacin, $\mathrm{LVX}_{5}$ : levofloxacin, $\mathrm{CTX}_{30}$ : cefotaxime, $\mathrm{CAZ}_{30}$ : ceftazidime

Prevalence of $\beta$-Lactamase-Producing Isolates: PCR amplification was used to verify ESBL production in 50 DDT-positive strains. The presence of ESBL-encoding genes in these 50 isolates was verified through molecular analysis. Of 100 patients with various types of cancer participated in this study, 50\% were ESBL-PE carrier. 
The existence of $b l a_{\text {TЕM' }}, b l a_{\text {SHV }}, b l a_{\text {СTX-M' }}$ and bla $a_{\text {СТх-м-15 }}$ genes in each organism was checked by PCR as explained before. The ESBL genes identified were as follows: bla ${ }_{\text {Стх-м }}$ (47 of 50;

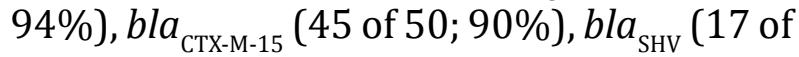
$50 ; 34 \%$ ), and bla $_{\text {TEM }}$ (40 of $50 ; 80 \%$ ) (Figure 2). The CTX-M group ESBL enzymes were identified in most of the isolates.

Gastrointestinal and breast cancers were the foremost diagnosed cancers among patients. It was also determined that cancer type had the most contribution to the fecal carriage of ESBL-PE. A remarkable rise in the prevalence
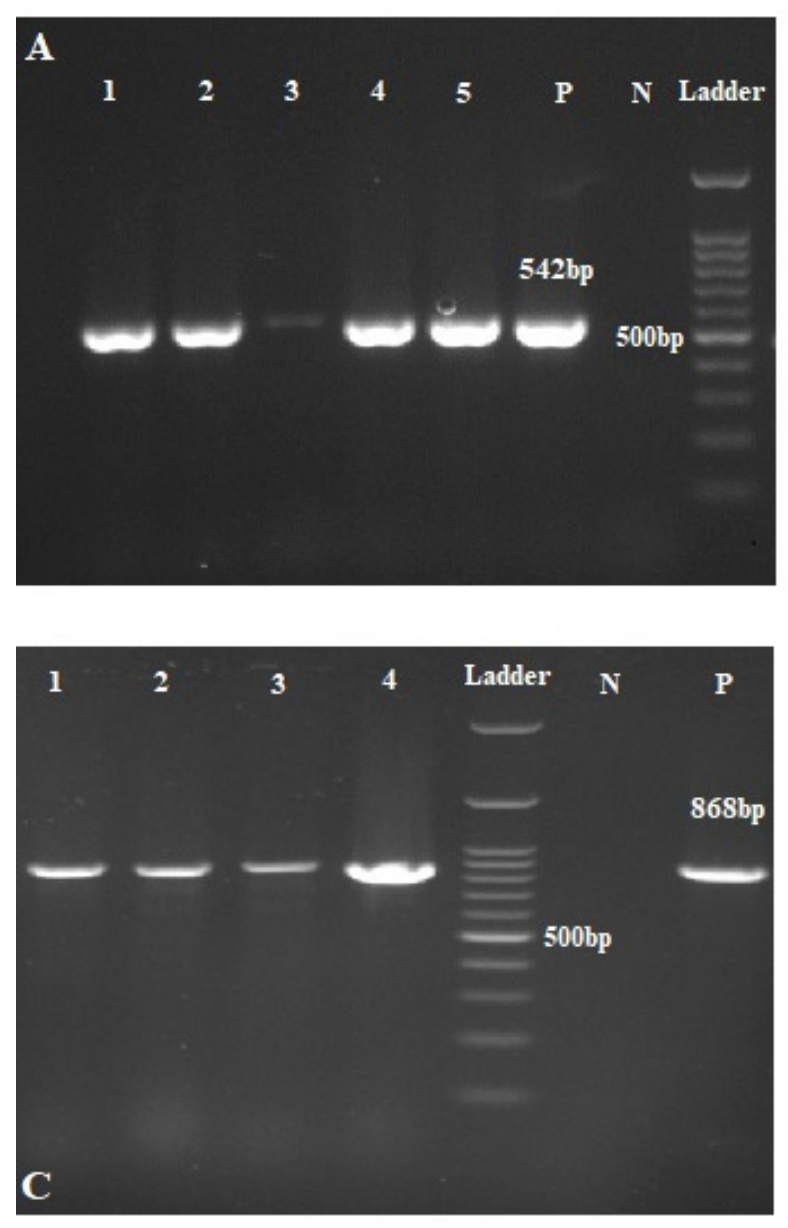

of ESBL-PE fecal carriage was found in gastrointestinal and genitourinary cancers. In other words, the prevalence rate of ESBLPE fecal carriage in cancer cases was 50\%, of which $40 \%$ was observed in patients with breast cancer, $67.5 \%$ in gastrointestinal cancer, $53.3 \%$ in genitourinary cancer, and $25 \%$ in other cancers (skin and lung) (Figure 3).

\section{Discussion}

Colonization of the gastrointestinal tract (GIT) with ESBL-PE is a significant risk factor for subsequent infections caused by
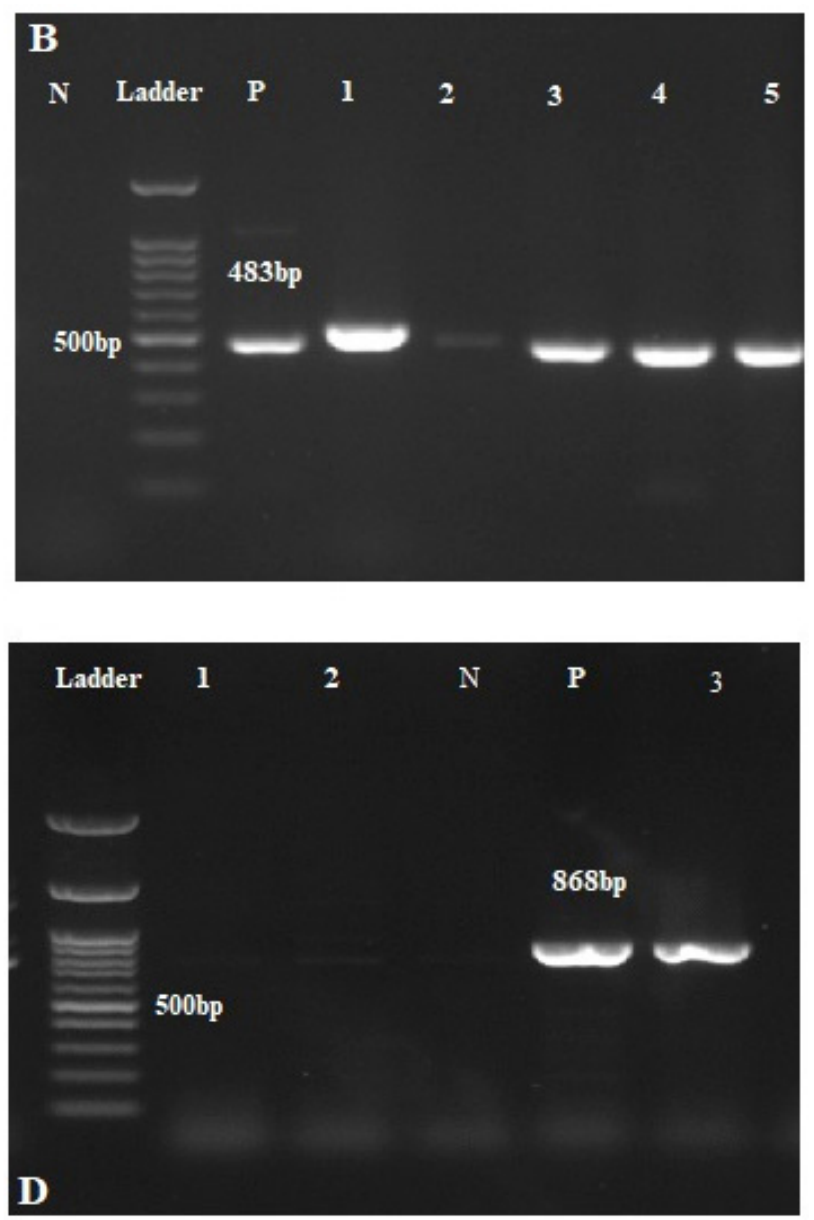

Fig. 2) PCR amplification products of extended-spectrum $\beta$-lactamase genes from Enterobacteriaceae isolates. (A) PCR amplification of blaCTX-M gene. Lane 1, 2, 3, 4, and 5: clinical isolates; Lane P: positive control; Lane N: negative control; and Lane ladder: DNA marker (100 bp). (B) PCR amplification of blaCTX-M-15 gene. Lane 1, 2, 3, 4, and 5: clinical isolates, Lane P: positive control; Lane N: negative control; and Lane ladder: DNA marker (100 bp). (C) PCR amplification of blaTEM gene. Lane 1, 2, 3, and 4: clinical isolates; Lane N: negative control; Lane P: positive control; and Lane ladder: DNA marker (100 bp). (D) PCR amplification of blaSHV gene. Lane 1, 2, and 3: clinical isolates; Lane $\mathrm{N}$ : negative control; Lane P: positive control; and Lane ladder: DNA marker (100 bp) 


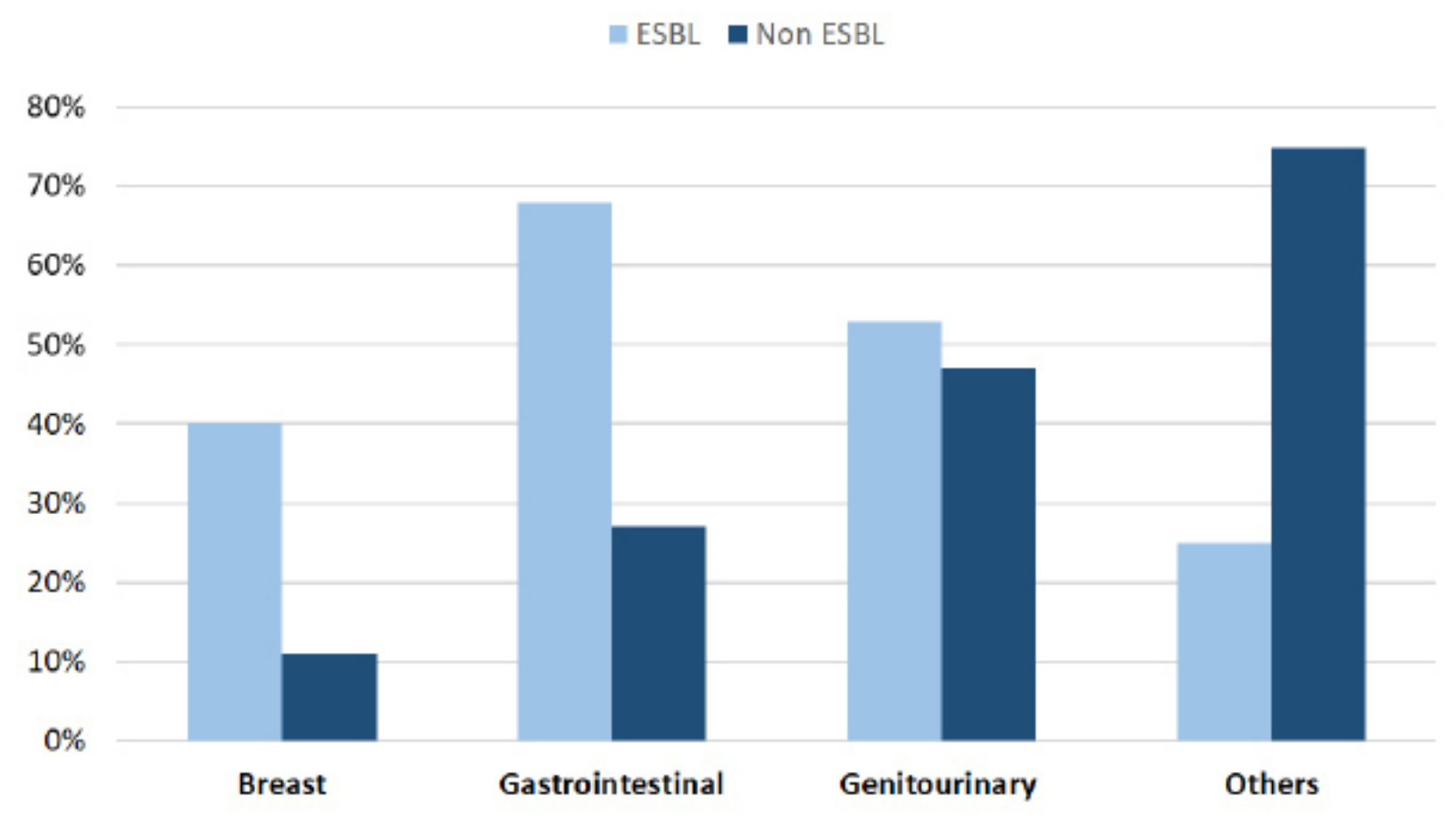

Fig. 3) The prevalence of ESBLs fecal carriage in different cancers

these resistant pathogens. GIT colonization is worrying in cancer cases because cytotoxic chemotherapy and prolonged use of broad-spectrum antibiotics alter the gut microbiome. The prevalence of ESBL-PE varies globally and is rapidly changing over time ${ }^{[6]}$. In eastern Iran, no data are available about ESBL fecal carriage in patients with cancer; thus, this research is the first study displaying alarmingly high prevalence of ESBL-PE colonization.

The prevalence of ESBL-PE fecal carriage in this study was $50 \%$, which is close to the finding reported by Medboua-Benbalagh et al. (2017) in an oncology pediatric unit in Algiers (54\%) ${ }^{[6]}$, but higher than that reported (31.8\%) in neutropenic patients with cancer in Spain [17]. It is also higher than the result previously recorded by Golzarri et al. (2019) (21\%) in patients with gastrointestinal and gynecological malignancies in Mexico City ${ }^{[18]}$. This vast variation in the prevalence rate of ESBL$\mathrm{PE}$ fecal carriage is possibly related to the diversity in the type of samples analyzed.
Overall, ESBL-producing E. coli strains were the most prevalent bacteria isolated from the fecal samples of 100 cancer patients studied. This finding is consistent with the results of recent studies in Spain, Mexico, Algeria, and Lebanon, which have reported alarmingly high levels of fecal colonization by ESBLproducing E. coli strains among neutropenic cases ${ }^{[6,17-19] \text {. }}$

The antibiotic susceptibility testing results in previous research by Montazeri et al. (2020) manifested high resistance of ESBL-PE strains, causing bloodstream infections (BSIs) in cancer cases, to b-lactam antibiotics like ceftazidime $(85.7 \%)$ and cefotaxime (76.1\%). In their study, amikacin, gentamicin, fluoroquinolones (ciprofloxacin, levofloxacin), and imipenem were identified as suitable antibiotics for the treatment of Enterobacteriaceae infections in cancer cases in the southwest of Iran due to their low resistance rate ${ }^{[16]}$. These findings are consistent with the present study results. However, these outcomes contradict the results of another research carried out by 
Medboua-Benbalagh ${ }^{[6]}$. Different patterns of antibiotic usage in various geographical areas and the difference in the age of the studied populations could be the major reasons for the discrepancy between these two studies results.

In the present research, bla $a_{\text {СтX-M }}$ with a prevalence rate of $94 \%$ was the most common gene among the isolates, followed by $b l a_{\text {СТХ-М- } 15}$ and $b l a_{\text {TЕм }}$ gene with a prevalence rate of 90 and $80 \%$, respectively, this finding is in line with the findings of other studies displaying the significance of bla $_{\text {СTX-M }}$ in different nations [16-18, 20].

In this study, the risk factors associated with ESBL-PE fecal carriage in cancer cases were also investigated. In line with several studies results ${ }^{[6,16]}$, there was no significant relationship between ESBL-PE fecal carriage and sex, age, history of chemotherapy, and time of diagnosis. No significant relationship was also found between ESBL$\mathrm{PE}$ fecal carriage and previous treatment with antimicrobial drugs. These findings are in line with those previously published by Knudsen et al. ${ }^{[21]}$ but in contrast with those reported by other researchers $[6,9,17$, $18,20]$. The discrepancy between different studies results could be due to differences in the study population, the amount of antibiotics used, and the type of antibiotics used in different countries, suggesting that the risk factors of bacterial resistance are multifactorial and complex in nature.

According to previous research, ESBLPE colonization is associated with the development of bloodstream infections and higher mortality in patients with weakened immune systems [6, 16, 22]. Thus, investigation of colonization with resistant bacteria in a variety of cancers might help specify infection-control practices and prevent further spread of ESBL-PE with limited therapeutic options. In this study, the prevalence of ESBLs varied dramatically between different cancers, ranging from $25 \%$ in skin and lung cancers to $67.5 \%$ in gastrointestinal cancer. Cancer type and ESBL-PE fecal carriage were found to have a considerable positive relationship. The higher rate of fecal colonization observed in patients with gastrointestinal cancer could be linked to regular use of endoscopic diagnostic techniques and management of gut obstruction. Contaminated endoscopes as medical apparatuses are often related to increased colonization rates with antibiotic-resistant bacteria. To the best of our knowledge, a limited number of studies have evaluated the association between the cancer type and ESBL-PE fecal carriage in cancer patients. In Medboua-Benbalagh's research, the rate of ESBL-PE fecal carriage in children with hematological malignancies was higher than in children with solid tumors, which confirms this study findings [6]. Montazeri et al. (2020) investigated the effect of cancer type on the prevalence of ESBL-PE causing bloodstream infections in cancer patients in southwestern Iran, and there was no relationship between the two [16].

There are some restrictions that must be mentioned. First, there are numerous potential problems when screening fecal samples. Although stool samples naturally produce a high yield of organisms, they are not always available. Second, the fecal samples studied in this research were gathered some years ago, and the restriction of the current research is the absence of information from the present time. It would be interesting to conduct such research right now in Iran.

\section{Conclusion}

In summary, the incidence of ESBL-PE fecal carriage in patients with various types of cancer was $50 \%$. The present study findings demonstrated that most ESBL-PE strains 
contained the CTX-M group enzymes. The cancer type had the most contribution to the fecal carriage. This research provides new information on the hidden reservoirs and features of the study population, which could aid in the development of infection control policies. Thus, to avoid the further distribution of ESBL-PE that has restricted therapeutic options, cancer patients should be controlled, and antibiotic stewardship plans ought to be performed.

\section{Acknowledgements}

The authors express their sincere thanks to Birjand University of Medical Sciences for its technical and financial support of this research.

Ethical Permission: Approval number in Birjand University of Medical Sciences is IR.BUMS.REC.1397,148.

Conflicts of Interests: All authors state that they have no competing interest.

Authors Contribution: Conceptualization: MHN; data curation: MHN, ARS, and PA; formal analysis: $\mathrm{FH}$ and PA; funding acquisition: MHN; investigation: PA and MM; methodology: MHN, ARS, and PA; project administration: MHN; resources: MHN; software: PA and $\mathrm{FH}$; supervision: $\mathrm{MHN}$ and ARS; writing of the original draft: PA; writing-review and editing: MHN.

Fundings: This research was supported by a grant from Birjand University of Medical Sciences (BUMS) (No: 455320), Iran.

Consent to participate: Written informed consents were obtained from participants.

\section{References}

1. Lin L, Jia L, Fu Y, Zhao R, Huang Y, Tang C, et al. A comparative analysis of infection in patients with malignant cancer: a clinical pharmacist consultation study. Journal of infection and public health. 2019;12(6):789-93.

2. Jiang A-M, Shi X, Liu N, Gao H, Ren M-D, Zheng X-Q et al. Nosocomial infections due to multidrugresistant bacteria in cancer patients: a sixyear retrospective study of an oncology Center in Western China. BMC Infectious Diseases. 2020;20(1):1-12.

3. Mahamat 00, Lounnas M, Hide M, Dumont Y, Tidjani A, Kamougam K, et al. High prevalence and characterization of extended-spectrum ß-lactamase producing Enterobacteriaceae in Chadian hospitals. BMC infectious diseases. 2019;19(1):1-7.

4. Ali T, Ali I, Khan NA, Han B, Gao J. The growing genetic and functional diversity of extended spectrum beta-lactamases. BioMed research international. 2018;2018.

5. ElMahallawy HA, Zafer MM, Amin MA, Ragab MM, Al-Agamy MH. Spread of carbapenem resistant Enterobacteriaceae at tertiary care cancer hospital in Egypt. Infectious Diseases. 2018;50(7):560-4.

6. Medboua-Benbalagh C, Touati A, Kermas R, Gharout-Sait A, Brasme L, Mezhoud H, et al. Fecal carriage of extended-spectrum $\beta$-lactamaseproducing Enterobacteriaceae strains is associated with worse outcome in patients hospitalized in the pediatric oncology unit of Beni-Messous Hospital in Algiers, Algeria. Microbial Drug Resistance. 2017;23(6):757-63.

7. Montassier E, Batard E, Gastinne T, Potel G, de La Cochetière M. Recent changes in bacteremia in patients with cancer: a systematic review of epidemiology and antibiotic resistance. European journal of clinical microbiology \& infectious diseases. 2013;32(7):841-50.

8. Arnan M, Gudiol C, Calatayud L, Liñares J, Dominguez M, Batlle M, et al. Risk factors for, and clinical relevance of, faecal extended-spectrum $\beta$-lactamase producing Escherichia coli (ESBLEC) carriage in neutropenic patients with haematological malignancies. European journal of clinical microbiology \& infectious diseases. 2011;30(3):355-60.

9. Gudiol C, Calatayud L, Garcia-Vidal C, LoraTamayo J, Cisnal M, Duarte R, et al. Bacteraemia due to extended-spectrum $\beta$-lactamaseproducing Escherichia coli (ESBL-EC) in cancer patients: clinical features, risk factors, molecular epidemiology and outcome. Journal of antimicrobial chemotherapy. 2010;65(2):33341.

10. Kim Y-J, Jung SM, Kang J, Ryoo SM, Sohn CH, Seo D-W, et al. Risk factors for extended-spectrum beta-lactamase-producing Enterobacteriaceae infection causing septic shock in cancer patients with chemotherapy-induced febrile neutropenia. Internal and emergency medicine. 2019;14(3):433-40.

11. Marin M, Gudiol C, Ardanuy C, Garcia-Vidal C, Calvo M, Arnan M, et al. Bloodstream infections in neutropenic patients with cancer: differences 
between patients with haematological malignancies and solid tumours. Journal of Infection. 2014;69(5):417-23.

12. SG S, Nath DR. Prevalence of ESBL and Amp $\mathrm{C}$ producing Enterobacteriaceae in a tertiary care cancer hospital in South India with special reference to E. coli and Klebsiellapneumoniae.

13. Clinical, Institute LS. Performance standards for antimicrobial susceptibility testing. Clinical and Laboratory Standards Institute Wayne, PA; 2017.

14. Joo E-J, Kim SJ, Baek M, Choi Y, Seo J, Yeom J-S, et al. Fecal carriage of antimicrobial-resistant Enterobacteriaceae in healthy Korean adults. J Microbiol Biotechnol. 2018;28:1178-84.

15. Sheikh AF, Moosavian M, Abdi M, Heidary M, Shahi F, Jomehzadeh N, et al. Prevalence and antimicrobial resistance of Shigella species isolated from diarrheal patients in Ahvaz, southwest Iran. Infection and drug resistance. 2019;12:249.

16. Montazeri EA, Khosravi AD, Saki M, Sirous M, Keikhaei B, Seyed-Mohammadi S. Prevalence of Extended-Spectrum Beta-Lactamase-Producing Enterobacteriaceae Causing Bloodstream Infections in Cancer Patients from Southwest of Iran. Infection and Drug Resistance. 2020;13:1319.

17. Calatayud L, Arnan M, Liñares J, Dominguez M, Gudiol C, Carratalà J, et al. Prospective study of fecal colonization by extended-spectrum$\beta$-lactamase-producing Escherichia coli in neutropenic patients with cancer. Antimicrobial agents and chemotherapy. 2008;52(11):418790.

18. Golzarri MF, Cornejo-Juárez P, Chora-Hernández LD, Vilar-Compte D. Colonization by fecal extended-spectrum b-lactamase-producing Enterobacteriaceae and surgical site infections in patients with cancer undergoing gastrointestinal and gynecologic surgery. 2019.

19. Christophy R, Osman M, Mallat H, Achkar M, Ziedeh A, Moukaddem W, et al. Prevalence, antibiotic susceptibility and characterization of antibiotic resistant genes among carbapenem- resistant Gram-negative bacilli and yeast in intestinal flora of cancer patients in North Lebanon. Journal of infection and public health. 2017;10(6):716-20.

20. Cornejo-Juárez P, Suárez-Cuenca JA, VolkowFernández P, Silva-Sánchez J, Barrios-Camacho H, Nájera-León E, et al. Fecal ESBL Escherichia coli carriage as a risk factor for bacteremia in patients with hematological malignancies. Supportive Care in Cancer. 2016;24(1):253-9.

21. Knudsen PK, Brandtzaeg P, Høiby EA, Bohlin J, Samuelsen $\varnothing$, Steinbakk $M$, et al. Impact of extensive antibiotic treatment on faecal carriage of antibiotic-resistant enterobacteria in children in a low resistance prevalence setting. PloS one. 2017;12(11):e0187618.

22. Melzer M, Petersen I. Mortality following bacteraemic infection caused by extended spectrum beta-lactamase (ESBL) producing E. coli compared to non-ESBL producing E. coli. Journal of Infection. 2007;55(3):254-9.

23. Moghanni M, Ghazvini K, Farsiani H, Namaei MH, Derakhshan M, Yousefi M, et al. High prevalence of sequence type 131 isolates producing CTX-M-15 among extended-spectrum $\beta$-lactamase-producing Escherichia coli strains in northeast Iran. Journal of global antimicrobial resistance. 2018;15:74-8.

24. Bourouis A, Belhadj O. Multidrug-resistant phenotype and isolation of a Novel SHVbeta-Lactamase variant in a clinical isolate of Enterobacter cloacae. Journal of Biomedical Science. 2015;22(1):1-7.

25. Namaei MH, Yousefi M, Ziaee M, Salehabadi A, Ghannadkafi M, Amini E, et al. First report of prevalence of CTX-M-15-producing Escherichia coli 025b/ST131 from Iran. Microbial Drug Resistance. 2017;23(7):879-84.

26. Hassuna NA, Khairalla AS, Farahat EM, Hammad AM, Abdel-Fattah M. Molecular characterization of Extended-spectrum $\beta$ lactamase-producing E. coli recovered from community-acquired urinary tract infections in Upper Egypt. Scientific reports. 2020;10(1):1-8. 